УДК $630 * 182: 630 * 411(571.5)$

НЕКОТОРЫЕ СОВРЕМЕННЫЕ ПОДХОДЫ К ИЗУЧЕНИЮ СОСТОЯНИЯ ЗЕЛЁНЫХ НАСАЖДЕНИЙ

\author{
Чжан С.А., Пузанова О.А. \\ ФГБОУ ВО «Братский государственный университет», Братск, e-mail: schzan@rambler.ru
}

\begin{abstract}
Братск относится к городам с нарушенной экологической обстановкой и является крупным промышленным центром Восточной Сибири. Одной из самых острых экологических проблем на сегодняшний день является проблема комплексной оценки зелёных насаждений. В связи с этим увеличение площадей зелёных насаждений, а также сохранение и повышение устойчивости существующих зон лесопарков - одна из первоочередных задач урботерриторий. В статье изложены основные полученные данные по оценке состояния зелёных насаждений при ведении мирмекологического мониторинга. При проведении работ по мониторингу отбирают насаждения полностью или только с наличием обильного поселения муравьёв. На обследуемой территории определяются только характерные виды для данного объекта изучения, составляющие основу ассоциации муравьёв. Каждый вид муравьёв характеризуется устойчивой приуроченностью к определенным условиям обитания, которые наилучшим образом соответствуют их видовым потребностям и где они, в связи с их социальной структурой, могут существовать долгое время. Изменение условий обитания в связи с естественным развитием биогеоценозов или стрессовым воздействием антропогенных факторов вынуждает муравьёв покидать освоенные биотипы или они деградируют и вымирают. Муравьи играют огромную роль в процессах улучшения почвенного и водного режимов для регуляции роста и развития растений. В целом работа муравьёв приводит к успешному возобновлению древостоев и способствует повышению их устойчивости. Оценка состояния насаждений осуществлялась глазомерным способом, путём детального осмотра каждого дерева. Определение характеристики мирмекофауны в городских лесах позволяет дополнить систему биомониторинга.
\end{abstract}

Ключевые слова: зелёные насаждения, мирмекологический мониторинг, лесопатологическое обследование, лесопарки, ландшафт

\title{
SOME MODERN APPROACHES TO THE STUDY OF GREEN PLANTINGS CONDITION
}

\section{Chzhan S.A., Puzanova O.A.}

Bratsk State University, Bratsk, e-mail: schzan@rambler.ru

\begin{abstract}
Bratsk refers to cities with disturbed environmental conditions, so it is a major industrial center of Eastern Siberia. One of the most acute environmental problems today is the problem of integrated assessment of green spaces. In this regard, the increase in the area of green space, as well as the preservation and improvement of the stability of existing areas of forest parks - one of the priorities of urban areas. The article presents the main data on the assessment of the state of green spaces in the conduct of myrmecological monitoring. When carrying out works on monitoring the plantings were selected having abundant settlements of ants. In the surveyed area, only the characteristic species for this object of study, which form the basis of the Association of ants, are determined. Each ant species is characterized by a stable Association with certain living conditions that best suit their species needs and where they may exist for a long period of time due to their social structure. Changing living conditions due to the natural development of biogeocenoses or the stress of anthropogenic factors forces ants to leave the developed biotypes or they degrade and die out. Ants play a huge role in the processes of improving soil and water regimes for the regulation of plant growth and development. In general, the work of ants leads to a successful resumption of stands and contribute to their sustainability. Assessment of plantations was carried out visually, through a detailed examination of each tree. The characterization of myrmecofauna in urban forests allows to supplement the biomonitoring system.
\end{abstract}

Keywords: green plantings, myrmecological monitoring, forest pathology examination, forest parks, landscape

Состояние зелёных насаждений крупных промышленных городов играет немаловажную роль: так, они служат местом рекреационного пользования и должны выполнять оздоровительные и эстетические функции лесов. Лесопарковые зоны создают микроклимат городов. Рекреационное лесопользование объективно способствует решению целого ряда задач социального характера.

Город Братск является одним из крупнейших промышленных городов Приангарья, в котором сосредоточено: алюминиевое производство; предприятия химической и целлюлозно-бумажной промышленности; предприятия теплоэнергетики. Основные источники загрязнения воздуха находятся очень близко друг к другу, за счет этого происходит перемешивание пылегазовых выбросов, что затрудняет определение доли участия каждого предприятия в загрязнении природной среды. Город Братск имеет сложный рельеф местности, повторяемость слабых ветров у поверхности почвы в разные месяцы года составляет $41 \%$, это все приводит к неблагоприятным условиям для рассеивания выбросов. 


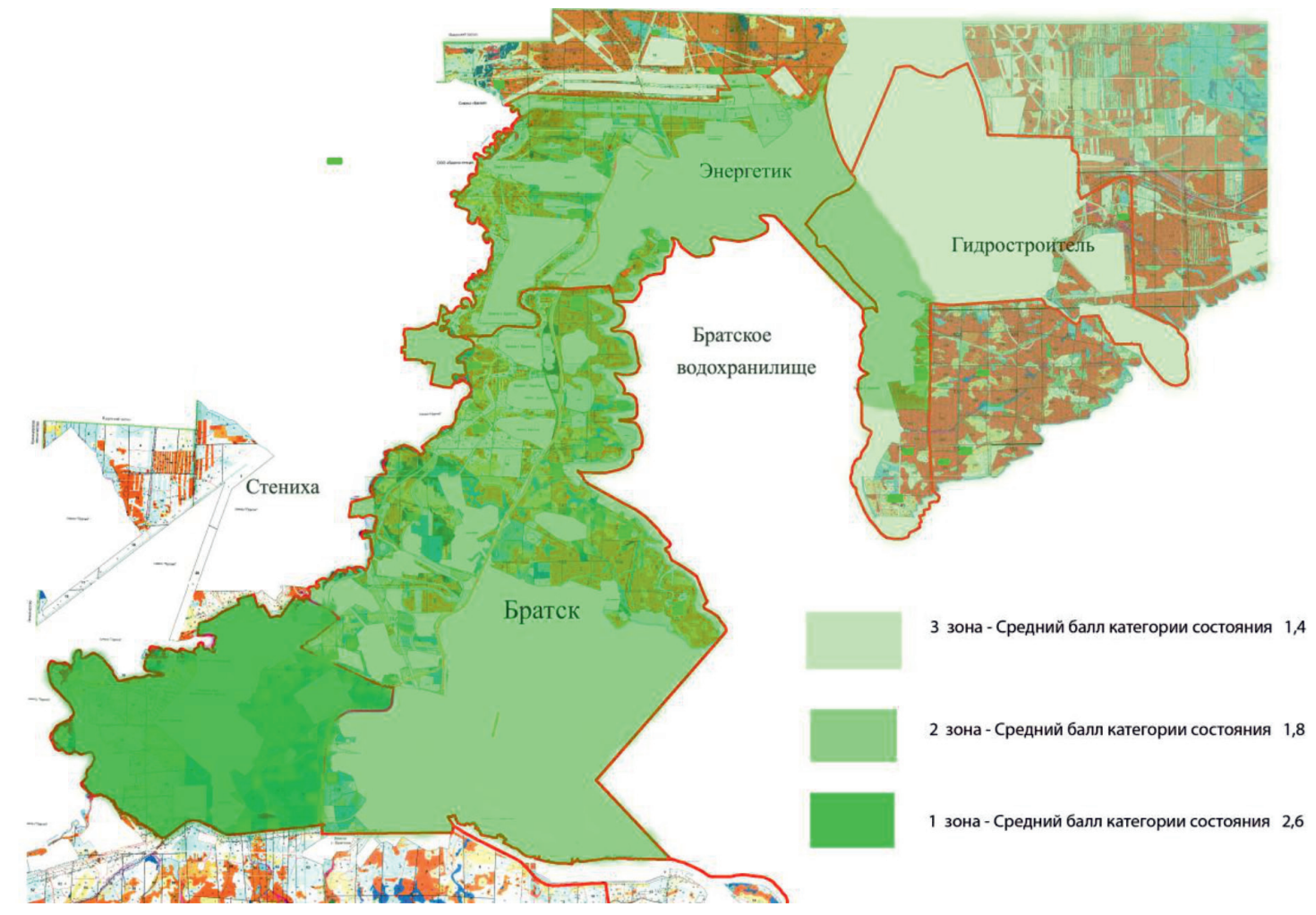

Рис. 1. Карта-схема г. Братска

При изучении состояния растительности зелёных насаждений обращали внимание на результаты многолетних наблюдений по влиянию различных токсичных газообразных веществ промышленных выбросов, которые в свою очередь оказывают существенное влияние на рост и развитие древесных пород.

Снижению эстетических качеств рекреационных лесов помимо техногенного загрязнения способствуют и представители фитопатогенов и энтомовредителей.

В настоящее время частично используют в комплексе проведения мониторинговых исследований использования муравьёв в лесных сообществах и общем экологическом мониторинге среды, которые служат индикатором состояния растительности $[1,2]$.

Цель исследования: проведение мирмекологического мониторинга в лесопарковых зонах г. Братска.

Для достижения цели исследования необходимо решить следующие задачи:

1. Сбор информационных показателей состояния муравейников и проведение их инвентаризации.

2. Изучение состояния насаждений в биотопах, заселенных муравьями.
3. Комплексная оценка состояния зеленых насаждений.

\section{Материалы и методы исследования}

Объектами исследования явились лесопарковые зоны г. Братска. Карта-схема зон влияния промышленного загрязнения (данное зонирование лесов г. Братска разработано [3] с расположением объектов исследования) приведена на рис. 1.

Инвентаризация муравейников включала в себя: определение видов муравьёв на обследуемой территории; описание насаждения, в котором находятся гнёзда.

На исследуемой территории были заложены учетные площадки, на которых производился учёт древостоев по общеизвестным методикам [4], по категориям состояния на основе шкал $[5,6]$.

При перечёте деревьев на учётных площадках отмечалось и патологическое изменение в состоянии [6].

Для обследования состояния насаждений были заложены пробные площади в количестве пяти штук размером $100 \times 100$ м. На каждой площади были измерены таксационные показатели у 40-100 деревьев и проведено лесопатологическое обследо- 
вание. Для оценки жизнеустойчивости древостоев использовали общепринятую шкалу, с помощью которой состояние выделено 4 классами: класс 1 - древостои совершенно здоровые с признаками хорошего роста и развития. В древостоях 1 класса жизнеустойчивости нормальная лесная обстановка, хороший подрост, подлесок и живой почвенный покров, здоровых деревьев не менее $90 \%$. Класс 2 - древостои здоровые, но с явно замедленным ростом, здоровых деревьев не менее $50 \%$. Класс 3 - древостои с резко выраженным замедленным ростом и развитием, неустойчивые, здоровых деревьев не менее $20 \%$. Класс 4 - древостои явно отмирающие, их невозможно оздоровить, распад древесного сообщества достиг такой степени, что лесной обстановки не чувствуется, здоровых деревьев менее 20\% [7].

Обработка полученных данных проводилась статистическими методами с использованием компьютерной программы Excel.

\section{Результаты исследования и их обсуждение}

Исследования проводились на территории трёх лесопарков г. Братска: 1 - расположен в жилом районе Энергетик; 2 - в жилом районе Падун; 3 - в центральной части г. Братска.

Исходя из представленных классификаций лесопарков [8], лесопарки относятся к закрытым ландшафтам, с равномерным размещением деревьев по площади и с высокой плотностью.

Исходя из представленной шкалы состояния древостоев, растительность лесопарков можно отнести ко 2 классу жизнеустойчивости и частично к 3 классу жизнеустойчивости.

Древесная растительность не отличается высоким биоразнообразием, преобладающей породой является сосна, подрост и кустарники присутствуют. Рельеф равнинный, тропиночная сеть развита хорошо.

По результатам исследований по каждой пробной площади были определены средние таксационные показатели древостоев (табл. 1).

В целом на всех обследуемых пробных площадях преобладают разновозрастные, высокопродуктивные древостои сосны обыкновенной (P. sylvestris).

В табл. 2 представлена лесопатологическая оценка состояния зелёных насаждений, из которой видно, что чаще встречаются здоровые деревья. Незначительная часть имеет признаки усыхания. На некоторых пробных площадях имеется наличие деревьев с нарушенной устойчивостью к грибным патогенам, чаще всего встречаются некрозно-раковые болезни древесных пород.

Для одного из дополнительных показателей в системе биомониторинга лесов использовали изучение мирмекофауны.

Средние таксационные показатели на пробных площадях

Таблица 1

\begin{tabular}{|c|c|c|c|c|c|c|c|}
\hline $\begin{array}{c}\text { № } \\
\text { п/П }\end{array}$ & Состав & $\mathrm{D}$, см & Н, м & А, лет & бонитет & запас & полнота \\
\hline 1. & $10 \mathrm{C}+\mathrm{Oc}$ & 34,9 & 23,2 & 90 & 2 & 75,9 & 0,6 \\
\hline 2. & $10 \mathrm{C}+\mathrm{Oc}, 5$ & 35,9 & 22,5 & 57 & 1 & 35,6 & 0,1 \\
\hline 3. & $10 \mathrm{C}$ & 23,1 & 21,5 & 63 & 1 & 23,3 & 0,2 \\
\hline 4. & $10 \mathrm{C}$ & 20,6 & 20,4 & 60 & 1 & 17,6 & 0,8 \\
\hline 5. & $10 \mathrm{C}$ & 23,4 & 20,0 & 45 & 1 & 16,8 & 0,6 \\
\hline
\end{tabular}

Признаки повреждений зелёных насаждений

Таблица 2

\begin{tabular}{|c|c|c|c|c|c|}
\hline \multirow{2}{*}{$\begin{array}{c}\text { № } \\
\Pi / \Pi\end{array}$} & \multirow{2}{*}{$\begin{array}{l}\text { Количество } \\
\text { деревьев, шт. }\end{array}$} & \multicolumn{3}{|c|}{ Признаки повреждений } & \multirow{2}{*}{$\begin{array}{c}\text { Деревья, } \\
\text { пораженные } \\
\text { болезнями, шт. }\end{array}$} \\
\hline & & Здоровые, шт. & Усыхающие, шт. & Сухостойные, шт. & \\
\hline 1. & 92 & 85 & 2 & 3 & 2 \\
\hline 2. & 41 & 38 & 2 & 1 & 0 \\
\hline 3. & 60 & 46 & 4 & 3 & 7 \\
\hline 4. & 60 & 60 & 0 & 0 & 0 \\
\hline 5. & 43 & 43 & 0 & 0 & 0 \\
\hline
\end{tabular}



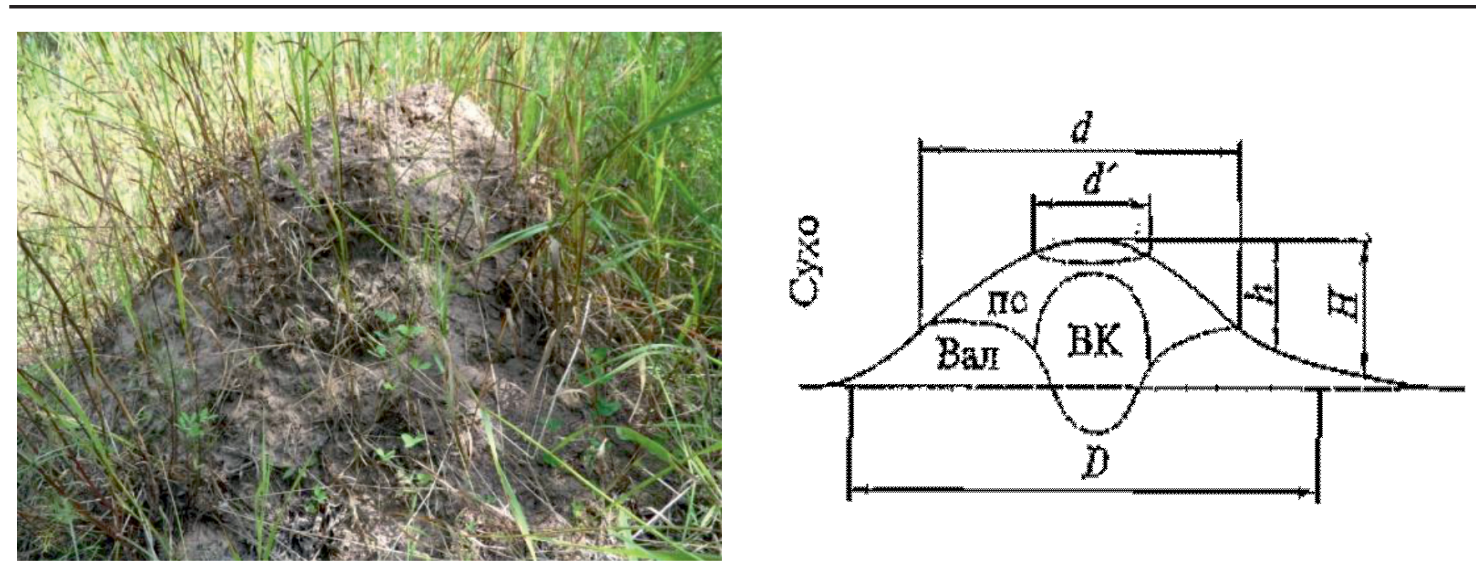

Рис. 2. Вид муравейника пробной площади 1: d-диаметр гнездового вала; D-диаметр наземного купола; d' - диаметр внутреннего конуса; $h$-высота купола гнезда; H-общая высота гнезда; $n c$ - покровный слой купола; ВК-внутренний конус гнезда [3]

В рекреационных и деградирующих лесах с нарушенным режимом произрастания древесных растений происходит постепенная деградация комплексов муравьёв, которая выражается во фрагментации единой системы семей, обособлении гнезд, депопуляции (превышение старых деградирующих гнезд над молодыми растущими) и гибели муравейников [1].

Инвентаризация муравейников проводилась в лесопарках по следующим маршрутам: на одном объекте обследовано 5 муравейников, находящихся на разном удалении от основной тропы; на 2-3 муравейника; на 3-5 муравейников.

На рис. 2 показан муравейник с плоской формой купола с установлением его основных размеров.

В лесопарке обитает серый песчаный муравей (Formica cinerea). На данной пробной площади характерно расположение гнезд только вдоль тропы. Муравейники имеют небольшую площадь основания и объем. Сезонная надстройка купола слабо выражена, наблюдается зарастание гнездового вала и купола травой, вялое движение рабочих особей, что свидетельствует о деградации муравейников. На основании данных по степени зарастания гнезд травой, муравейники отнесены к 3 и 4 степени деградации.

В табл. 3 приведены размеры муравейников на территории лесопарка центральной части г. Братска.

В табл. 4 приведены размеры муравейников на территории лесопарка жилого района Падун.

В парке Падун обитает малый лесной муравей (Formica polyctena). Муравейники располагаются на поляне с наличием подроста сосны и осины. Отличительной особенностью является расположение гнезд треугольником. На куполе муравейника хорошо заметна сезонная надстройка и заметное движение муравьев. По данным степени зарастания травой муравейники отнесены ко 2 и 3 степени деградации.

В табл. 5 приведены размеры муравейников на территории лесопарка жилого района Энергетик.

В этом парке обитает рыжий лесной муравей (Formica rufa). Муравейники отличаются внушительными размерами и значительными площадью основания и объемами. Гнезда располагаются на пне, камне, чем отличаются от расположения муравейников на других пробных площадях. Наблюдается хорошо заметная сезонная надстройка с более светлой хвоёй. На гнёздах большое скопление рабочих, движение их оживленное. На данной пробной площади муравейники отнесены к 1 и 2 степени деградации, так как степень зарастания купола и вала травой незначительна.

Наибольшую среднюю высоту и диаметр имеют муравейники, расположенные в парке Энергетик, это свидетельствует о том, что данные муравейники развиваются нормально, численность особей большая, наблюдается высокая охотничья активность муравьев. Следовательно, состояние древостоя парка лучше, чем в парках Падун и центральной части, так как территория парка сильнее защищена от вредителей, а также улучшено состояние почв, за счет рыхления при строительстве гнезд. 
Таблица 3

Размеры муравейников на территории лесопарка центральной части г. Братска

\begin{tabular}{|c|c|c|c|c|c|c|c|c|c|c|c|}
\hline \multirow[b]{2}{*}{ 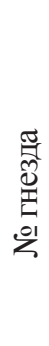 } & \multirow[b]{2}{*}{ 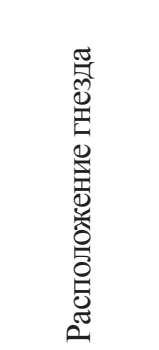 } & \multicolumn{2}{|c|}{ Диаметр, м } & \multicolumn{2}{|c|}{ Высота, м } & \multirow[b]{2}{*}{ 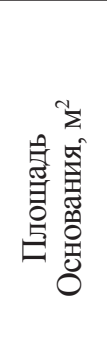 } & \multirow[b]{2}{*}{ 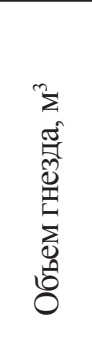 } & \multirow[b]{2}{*}{ 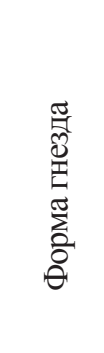 } & \multirow[b]{2}{*}{ 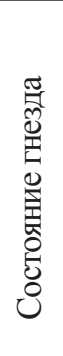 } & \multicolumn{2}{|c|}{$\begin{array}{l}\text { Степень зарас- } \\
\text { тания травой, \% }\end{array}$} \\
\hline & & 菛 & $\begin{array}{l}\text { 苟 } \\
\text { 窝 }\end{array}$ & $\begin{array}{l}\text { 产 } \\
\text { 后 } \\
0\end{array}$ & 菅 & & & & & 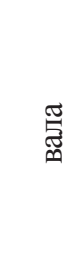 & 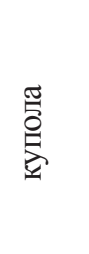 \\
\hline 1 & $\begin{array}{l}\text { Вдоль } \\
\text { тропы }\end{array}$ & 0,35 & 0,30 & 0,18 & 0,12 & 0,07 & 0,007 & Пл & $\mathrm{y}$ & 90 & 60 \\
\hline 2 & $\begin{array}{l}\text { Вдоль } \\
\text { тропы }\end{array}$ & 0,43 & 0,30 & 0,13 & 0,03 & 0,07 & 0,007 & Пл & Op & 90 & 70 \\
\hline 3 & На поляне & 0,36 & 0,34 & 0,42 & 0,13 & 0,10 & 0,007 & Вк(ск) & Op & 80 & 30 \\
\hline 4 & $\begin{array}{l}\text { Вдоль } \\
\text { тропы }\end{array}$ & 0,49 & 0,37 & 0,18 & 0,11 & 0,13 & 0,007 & Шл & Op & 90 & 70 \\
\hline 5 & $\begin{array}{l}\text { Вдоль } \\
\text { тропы }\end{array}$ & 0,40 & 0,25 & 0,28 & 0,19 & 0,04 & 0,007 & Шл & $\mathrm{y}$ & 90 & 80 \\
\hline
\end{tabular}

Состояние муравейников в парке на набережной пос. Падун

Таблица 4

\begin{tabular}{|c|c|c|c|c|c|c|c|c|c|c|c|}
\hline \multirow[b]{2}{*}{ 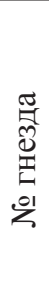 } & \multirow{2}{*}{ 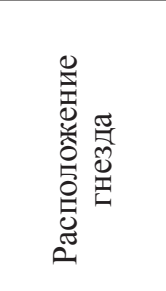 } & \multicolumn{2}{|c|}{ Диаметр, м } & \multicolumn{2}{|c|}{ Высота, м } & \multirow{2}{*}{ 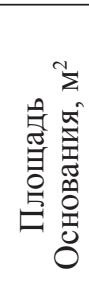 } & \multirow{2}{*}{ 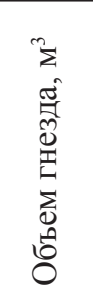 } & \multirow{2}{*}{ 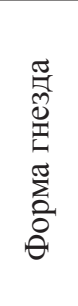 } & \multirow{2}{*}{ 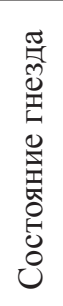 } & \multicolumn{2}{|c|}{$\begin{array}{c}\text { Степень зараста- } \\
\text { ния травой, \% }\end{array}$} \\
\hline & & 嗬 & $\begin{array}{l}\text { 莺 } \\
\text { 晃 }\end{array}$ & 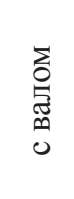 & $\begin{array}{l}\text { 营 } \\
\text { 窎 }\end{array}$ & & & & & 急 & 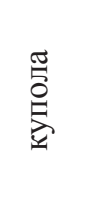 \\
\hline 1 & На поляне & 0,48 & 0,44 & 0,40 & 0,17 & 0,17 & 0,007 & Шл & Op & 70 & 50 \\
\hline 2 & На поляне & 0,70 & 0,64 & 0,50 & 0,27 & 0,33 & 0,024 & $\mathrm{C \phi}$ & Op & 60 & 40 \\
\hline 3 & На поляне & 0,88 & 0,73 & 0,55 & 0,20 & 0,46 & 0,073 & Шл & $\mathrm{P}$ & 70 & 30 \\
\hline
\end{tabular}

Состояние муравейников в парке жилого района Энергетик

Таблица 5

\begin{tabular}{|c|c|c|c|c|c|c|c|c|c|c|c|}
\hline \multirow[b]{2}{*}{ 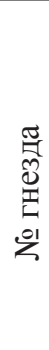 } & \multirow[b]{2}{*}{ 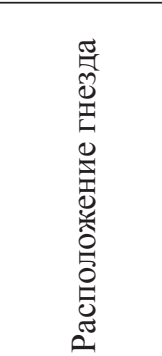 } & \multicolumn{2}{|c|}{ Диаметр, м } & \multicolumn{2}{|c|}{ Высота, м } & \multirow[b]{2}{*}{ 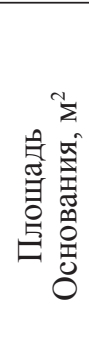 } & \multirow[b]{2}{*}{ 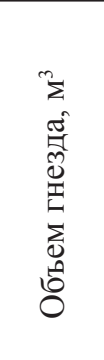 } & \multirow[b]{2}{*}{ 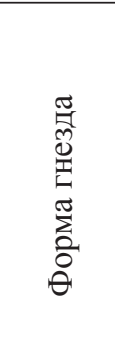 } & \multirow[b]{2}{*}{ 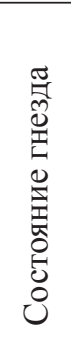 } & \multicolumn{2}{|c|}{$\begin{array}{l}\text { Степень зараста- } \\
\text { ния травой, \% }\end{array}$} \\
\hline & & 喼 & 营 & 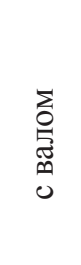 & 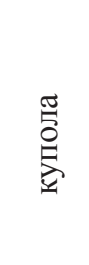 & & & & & 急 & $\begin{array}{l}\text { 总 } \\
\text { 宓 }\end{array}$ \\
\hline 1 & $\begin{array}{l}\text { Вдоль } \\
\text { тропы }\end{array}$ & 0,65 & 0,55 & 0,50 & 0,26 & 0,24 & 0,007 & Пл & $\mathrm{y}$ & 70 & 0 \\
\hline 2 & На пне & 0,95 & 0,80 & 0,68 & 0,36 & 0,52 & 0,073 & Вк(ск) & Op & 50 & 10 \\
\hline 3 & На камне & 0,70 & 0,60 & 0,45 & 0,22 & 0,27 & 0,011 & $\mathrm{~K}$ & $\mathrm{P}$ & 40 & 20 \\
\hline 4 & На поляне & 0,45 & 0,40 & 0,33 & 0,14 & 0,13 & 0,007 & K & $\mathrm{P}$ & 10 & 0 \\
\hline 5 & На поляне & 1,20 & 1,10 & 0,43 & 0,22 & 0,95 & 0,068 & Сф & Op & 0 & 0 \\
\hline
\end{tabular}




\section{Выводы}

По результатам работы можно отметить следующее:

1. В исследуемых лесопарках древесная растительность представлена сосной обыкновенной (P. sylvestris), напочвенный покров представлен травостоем средним по высоте, густоте, неоднородным (костяника (R. saxatilis), вейник тростниковидный (C. arundinacea), ветреница отогнутая (A. reflexa), василистник малый (Th. minus), фиалка одноцветковая (V. uniflora), вороний глаз мутовчатый (Paris verticillata), орляк обыкновенный (P. aquilinum) и др.). Лесопарки относятся к группе ландшафта закрытых пространств, с древостоями горизонтальной сомкнутости $0,6-1,0$ с равным размещением деревьев.

2. Исходя из представленной шкалы состояния древостоев, растительность лесопарков можно отнести ко 2 классу жизнеустойчивости и частично к 3 классу жизнеустойчивости, так как имеется наличие деревьев до $25 \%$ с явно замедленным ростом и развитием.

3. Возраст произрастающих насаждений на территории изучаемых объектов (средневозрастные) объясняет встречаемость следующих видов муравьёв: серый песчаный муравей (Formica cinerea), рыжий лесной муравей (Formica rufa), малый лесной муравей (Formica polyctena).

4. По результатам инвентаризации муравейников можно сделать вывод о том, что на каждом маршруте исследования наблюдалась различная степень их деградации. Это напрямую связано с удаленностью от основного источника загрязнения (алюминиевый завод).

5. Результаты исследований по изучению мирмекофауны можно использовать в качестве одного из дополнительных показателей при проведении комплексной оценки состояния лесов.
Интегральным выражением положительной роли муравьёв в биогеоценозах является общее повышение биологической устойчивости и продуктивности леса [2].

\section{Список литературы / References}

1. Голосова М.А. Муравьи в лесных экосистемах. Морфология, экология видов, инвентаризация и картирование комплексов. Организация мирмекологического мониторинга. М.: ГОУ ВПО МГУЛ, 2007. 65 с

Golosova M.A. Ants in forest ecosystems. Morphology, ecology of species, inventory and mapping of complexes. Organization myrmecological monitoring. M.: GOU VPO at MSFU, 2007. 65 p. (in Russian).

2. Захаров А.А., Длусский Г.М., Горюнов Д.Н., Гилёв А.В., Зрянин В.А., Федосеева Е.Б., Гороховская Е.А., Радченко А.Г. Мониторинг муравьев формика. Информационно-методическое пособие. М.: КМК, 2013.99 с.

Zakharov A.A., Dlusskiy G.M., Goryunov D.N., Gilev A.V., Zryanin V.A., Fedoseeva E.B., Gorokhovsky E.A., Radchenko A.G. Formica ants Monitoring. Information and methodological manual. M.: KMK, 2013. 99 p. (in Russian).

3. Чжан С.А. Зонирование лесных экосистем, подверженных длительному техногенезу // Вестник МГУЛ: Лесной вестник. 2012. № 1. C. 164-166.

Zhang S.A. Zoning of forest ecosystems exposed to longterm technogenesis // Vestnik MGUL: Forest Vestnik. 2012. № 1. P. 164-166 (in Russian).

4. Минаев В.Н., Леонтьев Л.Л., Ковязин В.Ф. Таксация леса: учебное пособие. СПб.: Лань, 2017. 240 с.

Minaev V.N., Leontyev L.L., Kovyazin V.F. Forest inventory: textbook. Saint-Petersburg: LAN, 2017. 240 p. (in Russian).

5. Правила санитарной безопасности в лесах Российской Федерации от 20 мая 2017 г. № 607. М., 2017. 14 с.

Rules of sanitary safety in the woods of the Russian Federation of may 20, 2017 № 607. M., 2017. 14 p. (in Russian).

6. Руководство по проведению санитарно-оздоровительных мероприятий (приложение 1 к приказу Рослесхоза от 15 мая 2015 года № 159). М., 2015. 32 с.

The management on carrying out sanitary and improving actions (appendix 1 to the order of Rosleskhoz of may 15, 2015. № 159). M., 2015. 32 p. (in Russian).

7. Чжан C.A., Пузанова О.А. Санитарное и лесопатологическое состояние лесов в Иркутской области// Системы. Методы. Технологии. 2016. № 2 (30). C. 174-178. DOI: 10.18324/2077-5415-2016-2-174-178.

Schang S.A., Puzanova O.A. Sanitary and forest pathology condition of the forests in Irkutskaya oblast // System. Methods. Technology. 2016. № 2 (30). P. 174-178 (in Russian).

8. Агальцова В.А. Основы лесопаркового хозяйства. М.: ГОУ ВПО МГУЛ, 2008. 213 с.

Agaltsova V.A. The Basics of forestry. M.: GOU VPO MGUL, 2008. 213 p. (in Russian). 